\title{
Aspects of the Theory of Environmental Policy in Developing Countries
}

\author{
AMITRAJEET A. BATABYAL ${ }^{\mathrm{a} *}$ and HAMID BELADI ${ }^{\mathrm{b}}$ \\ ${ }^{a}$ Department of Economics, Rochester Institute of Technology, 92 Lomb Memorial Drive, Rochester, NY 14623-5604, USA \\ ${ }^{\mathrm{b}}$ Department of Economics and Finance, University of Dayton, 300 College Park, Dayton, OH 45469-2251, USA
}

(Received 8 February 2001)

\begin{abstract}
We study two issues relating to the conduct of environmental policy in developing countries (DCs). First, when faced with a self-financing constraint, should an environmental authority (EA) raise/lower pollution taxes over time or should it run a deficit/surplus? Second, given recent findings about the dynamic inconsistency of optimal environmental policy, should an EA make its preferences about the relative benefits of environmental protection versus production public, or should it keep its preferences private? Our analysis reveals that when faced with a self-financing constraint, it is optimal for the EA to run a deficit/surplus. Second, social losses are lower when this EA keeps its preferences private.
\end{abstract}

Keywords: Developing country; Dynamic consistency; Environmental policy; Taxation

JEL Classification: O29; Q28

\section{INTRODUCTION}

In contemporary times, the connections between the environment and development have come to dominate academic and public debate in most parts of the world. Three principal issues have been articulated by scholars working in this area. First, Bhalla (1992), Renner (1992) and Mehmet (1995) have made the case that it is important for developing countries (hereafter DCs) to implement policies that generate employment. Second, Goldin and Winters (1995) and Faucheux et al. (1996), and more generally the sizeable literature on sustainable development $\dagger$ have stressed the need for instituting policies that protect the environment for the present and the future generations. Third, Batabyal (1998), Batabyal and Beladi (1999) and Lee and Batabyal (1999) have pointed out that under certain circumstances, employment creation and environmental protection are competing goals. What this means is that although DCs may begin the process of implementing environmental policies, over time, their commitment to such policies is likely to wane.

The purpose of this paper is to study two aspects of the above mentioned third issue. We analyze these two aspects by developing an alternate theoretical framework from that employed in Batabyal (1998), Batabyal and Beladi (1999) and Lee and Batabyal (1999). One of the key findings of these three papers is that in a dynamic setting, it is generally optimal for an environmental authority (hereafter EA) to alter the magnitude of pollution taxes over time. However, in many DCs, once pollution taxes have been set, from a political perspective, it is difficult to change-and in particular to raise-them. $\neq$ Further, on account of litigation, ${ }^{\natural}$ the need to grant subsides, ${ }^{\S}$ and other reasons, EAs in many DCs incur substantial

\footnotetext{
*Corresponding author. E-mail: aabgsh@rit.edu

${ }^{\dagger}$ For more on this literature, the reader should consult Atkinson et al. (1997), Farmer and Randall (1997), Pezzey (1997) and Heal (1998).

FFor more on this in the case of India, see Dwivedi, (1997, p. 103 and p. 203).

"Environmental litigation in China is discussed in Sinkule and Ortolano (1995). Dwivedi (1997), Mehta et al.(1997) discuss environmental litigation in India.

${ }^{\S}$ See Sinkule and Ortolano (1995, pp. 131-133) for subsidies in China and Dwivedi, (1997, pp. 118-121) for subsidies in India.
} 
expenses in performing their regulatory duties." Indeed, as Sinkule and Ortolano (1995, p.143) have noted, in China, EAs see "their ability to pursue pollution control as directly linked to their own financial strength..." This discussion raises a hitherto unanswered question about the nature of dynamic environmental policy in the presence of a (possibly) binding financial or budget constraint. ${ }^{\#}$ Consequently, we shall analyze the following question: When faced with a self-financing or budget constraint, is it still optimal for an EA to alter the trajectory of pollution taxes over time? Or, depending on the actual expenses incurred, does it make more sense to run deficits/surpluses? This is the first question that is analyzed in this paper.

The next question that we analyze is motivated by the findings in Batabyal (1998), Batabyal and Beladi (1999) and Lee and Batabyal (1999). These papers have shown that dynamic environmental policy in DCs is typically marked by an inability of the appropriate EA to commit to its announced course of action. In other words, the announced policy is dynamically inconsistent. Now given the dynamic inconsistency of optimal environmental policy, and the scant attention that this issue has received in the literature, one can ask what connection there exists between an EA's preferences and credible environmental policy. Specifically, should an EA make its preferences about the relative benefits of environmental protection versus production of the polluting good public, or should it keep its preferences private? This is the second question that we analyze.

The rest of this paper is organized as follows: the second section analyzes a model of environmental policy in which the EA is constrained by the presence of a self-financing (budget) constraint. The third section studies a model of credibility in the conduct of environmental policy. The fourth section concludes and offers suggestions for future research.

\section{ENVIRONMENTAL POLICY WITH A SELF- FINANCING CONSTRAINT}

\section{Preliminaries}

This section's model is adapted from Barro (1979). As in Batabyal (1998), we shall focus on a small, open, infinite horizon DC whose economy is dualistic. One sector is the traditional sector in which there is no pollution. The second sector is the modern sector in which production causes pollution. In the rest of this paper, our attention will be on this polluting sector. Let $q_{\mathrm{i}>/ \mathrm{i}>}$ denote the output of the polluting sector at time $t$, and let $\tau_{t}$ denote the tax levied by the EA on the production of this polluting good. Time is discrete and the price of the polluting good is normalized to unity. As a result of the imposition of this tax, the "socially correct" output of the polluting sector at time $t$ is not $q_{t}$ but $q_{t}-a \tau_{t}^{2} / 2$, where $a>0$ is a parameter.

The representative consumer of this polluting good has a subjective time preference factor $\beta$. The interest rate is $r$. We suppose that $\beta=1 /(1+r)$. Denote this consumer's period $t$ consumption by $c_{t}$, and his utility from consumption $c_{t}$ by $u\left(c_{t}\right)^{* *}$

As indicated in the "Introduction" section, in the course of performing its regulatory functions, the EA necessarily incurs expenses in every time period. We model the necessity of this expenditure by letting the amount spent in each time period, $e_{t}$, be exogenous. The national government in the DC funds the $\mathrm{EA}-g_{t}$ per time period-for the discharge of its regulatory functions. From the EA's perspective, this allocation of funds is also exogenous. ${ }^{\dagger \dagger}$ We can now write this EA's self-financing (budget) constraint as

$$
\sum_{s=t}^{\infty}\left[\frac{1}{1+r}\right]^{s-t}\left(\tau_{s}+g_{s}-e_{s}\right)=0 .
$$

In addition to its environmental functions, the EA maximizes the representative consumer's lifetime utility. In other words, the EA chooses the time path of private consumption and pollution taxes to solve

$$
\max _{\left\{c_{s}, \tau_{s}\right\}} \sum_{s=t}^{\infty}\left[\frac{1}{1+r}\right]^{s-t} u\left(c_{s}\right)
$$

There are two other constraints on the EA's problem. The first is the polluting sector's budget constraint. This constraint is

$$
\sum_{s=t}^{\infty}\left[\frac{1}{1+r}\right]^{s-t}\left[q_{s}-\frac{a \tau_{s}^{2}}{2}-\tau_{s}-c_{s}\right]=0 .
$$

The second constraint arises from the nature of the EA's optimization problem. Because the subjective time preference factor equals the market discount factor $(\beta=$ $1 /(1+r))$, the representative consumer's Euler equation for consumption in any two time periods $s$ and $s+1$ is ${ }^{*}$

$$
u^{\prime}\left(c_{s}\right)=u^{\prime}\left(c_{s+1}\right)
$$

where the prime denotes a derivative.

\footnotetext{
"Even when a legal proceeding has been instituted against non-compliant polluting firms, there is no assurance that this legal proceeding will result in success. For instance, In India, the prosecution success rate in 1992 in air and water pollution cases was 65 and 62\%, respectively, (Mehta et al. 1997, pp. 23-24).

"For more on the practical effects of budget constraints on the activities of EAs in China and India, see Sinkule and Ortolano (1995, p. 29) and Dwivedi (1997, pp. 124-125), respectively.

${ }^{* *}$ Note that consumption may be direct or indirect. For instance, in India, paper and sugar production are highly polluting activities (see Mehta et al., 1997, pp. 10-108). It is clear that in the case of sugar, consumption is direct. However, with regard to paper, consumption may be direct or indirect.

The reader will note that this rules out the possibility of the EA lobbying for additional funds.

For more on this, see Obstfeld and Rogoff (1996.p. 3).
} 


\section{Analysis and Results}

The EA maximizes Eq. (2) subject to the constraints given in Eqs. (1), (3), and (4). ${ }^{\uparrow \uparrow}$ Let $\gamma$ and $\delta$ be the Lagrange multipliers on constraints (1) and (3), respectively. Equation (4) tells us that the desired level of intertemporal consumption is constant at some level, say, $c \mathrm{O}$. Taking this into account, the Lagragian to problem (2) is

$$
\begin{aligned}
L= & \frac{1+r}{r}[u(\hat{c})-\delta c]-\sum_{s=t}^{\infty}\left[\frac{1}{1+r}\right]^{s-t} \\
& \times\left[\gamma\left(\tau_{s}+g_{s}-e_{s}\right)+\delta\left(q_{s}-\frac{a \tau_{s}^{2}}{2}-\tau_{s}\right)\right] .
\end{aligned}
$$

Differentiating Eq. (5) w.r.t. $\hat{c}$ and $\tau_{s}, \forall s>t$, we get the relevant first order conditions. These are

$$
u^{\prime}(\hat{c})=\delta
$$

and

$$
\gamma-u^{\prime}(\hat{c})=u^{\prime}(\hat{c}) a \tau_{s} .
$$

Equation (6) tells us that at the optimum, the marginal utility of consumption equals the shadow value of the polluting sector's resources. Equation (7) is more instructive. This equation says that at the optimum, there is a wedge between the shadow value of the EA's resources and the private value of consumption. This wedge (the LHS) equals the marginal deadweight loss of the pollution tax measured in terms of the representative consumer's utility.

It is important to note that both the shadow value of the EA's resources $(\gamma)$ and the private value of consumption $\left(u^{\prime}(\hat{c})\right)$ are constant over time. This means that in our model, optimal pollution taxes are also constant over time. Put differently, like the representative consumer-who finds it optimal to smooth consumption over time- the EA also finds it optimal to smooth pollution taxes over time. The constant pollution tax can be computed from Eq. (7). We get

$$
\hat{\tau}=\frac{\gamma-u^{\prime}(\hat{c})}{a u^{\prime}(\hat{c})}
$$

where $\gamma$ satisfies

$$
\gamma=u^{\prime}(\hat{c})+\left[\frac{r}{1+r}\right] u^{\prime}(\hat{c}) \sum_{s=t}^{\infty}\left[\frac{1}{1+r}\right]^{s-t} a\left\{e_{s}-g_{s}\right\}
$$

Equation (9) tells us that the EA's shadow value of resources (the LHS) equals the private value of consumption plus a weighted average of present and future marginal consumption costs arising from the difference between the necessary and exogenous stream of EA expenditures and government allotted funds. Put differently, at the optimum, there is a wedge between the shadow value of the EA's resources and the private value of consumption. This discussion highlights the fact that the EA's budget constraint has a very real effect on the optimal values of all the endogenous variables and in particular on the values of the optimal pollution taxes.

Because there is an optimal level of the pollution taxes, we can infer the following: Depending on the magnitude of the exogenous expenditures $e_{t}$, it will be optimal for the EA to run either a deficit or a surplus. We now summarize our main conclusions in

Proposition 1. When faced with a self-financing constraint, the EA should set a constant pollution tax over time. When its expenditures, $e_{t}$, are unusually high, it will be optimal for the EA to run a deficit. Similarly, when its expenditures are unusually low, the EA should run a surplus.

This concludes the second section. We now study a model of credibility in the conduct of environmental policy.

\section{CREDIBILITY AND ENVIRONMENTAL POLICY}

\section{Preliminaries}

One of the tasks of the EA of the previous section is to set appropriate pollution taxes $\tau_{t}$. In turn, these pollution taxes directly affect $q_{t}$, the production of the polluting good, and indirectly affect pollution $x_{t}$. In order to work with pollution directly, we suppose that the functional relationships between $x_{t}, q_{t}$, and $\tau_{t}$ are strictly monotonic. Formally, this will enable us to treat pollution and not pollution taxes as the EA's control variable. More informally, this will permit us to think of the EA as a "command-and-control" entity that sets pollution levels directly. Moreover, because we want to work with a loss function, it will be helpful to think of the EA as an entity that sets pollution levels (the bad) directly.

To reiterate, we shall think of $x_{t}$, as the period $t$ pollution level that is set by the EA in our DC. Let $x_{t}^{e}$ denote the polluting sector's period $t-1$ expectation of what pollution will be in period $t$.

Assuming that all agents in our DC have rational expectations, we get $x_{t}^{e} \equiv E_{t-1} x_{t}$, where $E[\cdot]$ is the expectation operator. There will generally be some discrepancy between the EA's targeted output level of the polluting good ${ }^{\S \S}$ and the actual output level. To this end, let $w>0$ denote the positive wedge between these two output levels. We suppose that the EA's preferences over pollution and the production of the polluting good

\footnotetext{
${ }^{\pi \rrbracket}$ Note that because both budget constraints bind in equilibrium, without loss of generality, we can express these two constraints as equalities.

${ }^{\S \S}$ As discussed in the previous paragraph, $x_{t}, q_{t}$, and $\tau_{t}$ are functionally related. Consequently, targeting pollution directly has the effect of targeting output indirectly.
} 
can be described by a loss function with the following form ${ }^{\text {III }}$

$$
\mathscr{L}_{t}=\frac{1}{2} x_{t}^{2}-\theta_{t}\left(x_{t}-x_{t}^{e}-w\right) .
$$

In Eq. (10), $\theta_{t}$ is a random variable with a two-point support. That is, $\theta_{t}=0$ with probability $p$ and $\theta_{t}=\Theta>0$ with probability $q=(1-p)$. The first term in the loss function in Eq. (10) reflects a concern for pollution and the second term reflects a concern for the output of the polluting good. It is important to comprehend the meaning of the random variable $\theta_{t}$. This random variable captures the effect of shocks that alter the relative benefits of pollution versus production. It can also be interpreted as the EA's "type." To see this, observe that $\theta_{t}=0 \Rightarrow \mathscr{L}_{t}=$ $(1 / 2) x_{t}^{2}$. This corresponds to the case of a "green" or "environmentalist" EA that does not care about production and is concerned solely with pollution. On the other hand when $\theta_{t}=\Theta$ we have a "conventional" EA that cares about both pollution and the production of the polluting good. From a political standpoint, a green EA is more likely with a liberal government in power and a conventional EA is more likely with a conservative regime in power.

\section{Analysis and Results}

Recall that we are interested in examining the link between the EA's preferences and credible environmental policy. Specifically, what we want to know is this: should the EA make its preferences-knowledge of $\theta_{t}$-about the relative benefits of environmental protection versus production public, or should it keep its preferences private? We shall answer this question in a series of steps.

Temporarily, let us suppose that the EA and the polluting sector interact only once. In this case, we want to compute the equilibrium levels of $x_{t}$ and $x_{t}^{e}$ in the one-shot game between the EA and the polluting sector. This is the discretionary case. To compute the equilibrium $x_{t}$, we shall take $x_{t}^{e}$ as given, and differentiate Eq. (10) w.r.t. $x_{t}$. The first order necessary condition is $x_{t}-\theta_{t}=0$, which tells us that in equilibrium

$$
x_{t}=\theta_{t}
$$

This says that in equilibrium, the optimal level of pollution equals the EA's type. To compute the equilibrium value of $x_{t}^{e}$, we shall use the definition of $x_{t}^{e}$, Eq. (11), and the assumption that all agents in the DC have rational expectations. This gives

$$
x_{t}^{e} \equiv E_{t-1} x_{t}=E_{t-1} \theta_{t}=p 0-q \Theta=q \Theta .
$$

In other words, the equilibrium expected level of pollution equals the expected value of the random variable denoting the EA's type. What is the expected loss to the EA in the discretionary one-shot game equilibrium? To answer this, we use Eqs. (10), (11) and (12). We get

$$
E_{t-1} \mathscr{L}_{t}^{D}=E_{t-1}\left[\theta_{t} q \Theta+\theta_{t} w-\frac{\theta_{t}^{2}}{2}\right]:
$$

Because $E_{t-1}\left[\theta_{t}^{2}\right]=q \Theta^{2}$, Eq. (13) can be simplified. This simplification yields

$$
E_{t-1} \mathscr{L}_{t}^{D}=(q \Theta)^{2}+q \Theta w-\frac{q \Theta^{2}}{2} .
$$

Having studied the one-shot discretionary game equilibrium and the associated expected loss to the EA, let us now focus on the notion of commitment. ${ }^{\# \#}$ We first want to compute the expected social loss from commitment $E_{t-1} \mathscr{L}_{t}^{C}$. We will then compare this loss with Eq. (14) to determine whether the expected loss to society under commitment is bigger or smaller than the expected loss with discretionary environmental policy. To compute $E_{t-1} \mathscr{L}_{t}^{C}$, suppose that the EA can commit to a best response function for $x_{t}\left(\theta_{t}\right)$. Let us compute the EA's optimal best response function given that $x_{t}^{e}=0$. In other words, we want to compute the EA's optimal best response function given that the polluting sector believes that the EA is "green." Formally, this constraint can be written as

$$
\operatorname{pxx}_{t}(0)+q x_{t}(\Theta)=0 .
$$

The EA's objective function is

$$
\begin{aligned}
E_{t-1} \mathscr{L}_{t}^{C}= & p\left[\frac{\left\{x_{t}(0)\right\}^{2}}{2}\right] \\
& +q\left[\Theta w+\frac{\left\{x_{t}(\Theta)\right\}^{2}}{2}-\Theta x_{t}(\Theta)\right] .
\end{aligned}
$$

Now incorporating the constraint (Eq. (15)) into Eq. (16), we can write the EA's problem as an unconstrained minimization problem. The EA solves

$$
\begin{aligned}
\min _{\left\{x_{t}(\Theta)\right\}} E_{t-1} \mathscr{L}_{t}^{C}= & \left\{x_{t}(\Theta)\right\}^{2}\left[\frac{q^{2}}{2 p}+\frac{q}{2}\right]+q \Theta w \\
& -q \Theta x_{t}(\Theta)
\end{aligned}
$$

The first order necessary condition to this problem is

$$
x_{t}(\Theta)\left[1+\frac{q}{p}\right]=\Theta
$$

\footnotetext{
IIII This kind of loss function has been used in the monetary economics literature by Barro and Gordon (1983) Backus and Driffil (1985), and others. For a good account of dynamic consistency issues in monetary economics, see Obstfeld and Rogoff (1996, pp. 634-658).

\#\# For an alternate perspective on commitment in environmental policy in DCs, see Batabyal (1998), Batabyal and Beladi (1999) and Lee and Batabyal (1999).
} 
Equation (18) and further simplification give us the optimal values of the two pollution levels. We get $x_{t}(\Theta)=$ $p \Theta$ and $x_{t}(0)=-q \Theta$. Substituting these two values into Eq. (16) gives us an equation for the optimized value of the expected social loss from commitment. That equation is

$$
E_{t-1} \mathscr{L}_{t}^{C}=q \Theta w-\frac{p q \Theta^{2}}{2}
$$

We can now determine whether society is better or worse off with the EA committing to environmental policy. The relevant equations to compare are Eqs. (14) and (19). Inspection of these two equations and some algebra gives us the required result. We state this result as

Proposition 2. $\forall p \in[0,1), E_{t-1} \mathscr{L}_{t}^{C}<E_{t-1} \mathscr{L}_{t}^{D}$. When $p=1, E_{t-1} \mathscr{L}_{t}^{C}=E_{t-1} \mathscr{L}_{t}^{D}$.

Proposition 2 tells us that in the general case, environmental policy with commitment results in lower social losses than does environmental policy with discretion. In other words, society is better off when the EA is committed to environmental policy. As one would expect, when there is no uncertainty about the EA's type, i.e. when $p=1$, committed and discretionary environmental policy result in the same loss to society.

We are finally in a position to answer the question posed at the beginning of this sub-section, i.e. should the EA make its preferences about the relative benefits of environmental protection versus production public, or should it keep its preferences private? Let us first analyze the case in which the EA reveals $\theta_{t}$ to the polluting sector. Suppose that the EA reveals $\theta_{t}$ on date $t-1$, before $x_{t}^{e}$ has been set by the polluting sector. In this case $x_{t}^{e}=\theta_{t}$. We will now compute the expected social loss from revelation on date $t-2$. $^{* * *}$ Substitute $x_{t}^{e}=\theta_{t}$ and Eq. (11) into Eq. (10), the EA's loss function, and then take expectations. We get

$$
E_{t-2} \mathscr{L}_{t}^{R}=q \Theta w+\frac{1}{2} q \Theta^{2}
$$

where the superscript $R$ denotes revelation.

When the EA keeps the true value of $\theta_{t}$ secret, the polluting sector forms its expectations about pollution in accordance with Eq. (12). In other words, $x_{t}^{e}=q \Theta$. Now substituting Eqs. (11) and (12) into Eq. (10), the EA's loss function, and then taking expectations, we get an equation for the expected social loss from secrecy. That equation is

$$
E_{t-2} \mathscr{L}_{t}^{S}=q \Theta w+(q \Theta)^{2}-\frac{1}{2} q \Theta^{2} .
$$

The superscript $S$ in Eq. (21) denotes secrecy. Now a comparison of Eqs. (20) and (21) and some algebra gives us the answer that we seek. We state this answer as
Proposition 3. $\forall q \in[0,1), E_{t-2} \mathscr{L}_{t}^{S}<E_{t-2} \mathscr{L}_{t}^{R}$. When $q=1, E_{t-2} \mathscr{L}_{t}^{S}=E_{t-2} \mathscr{L}_{t}^{R}$.

Proposition 3 tells us that in the general case, the EA will prefer to precommit itself to not reveal $\theta_{t}$ before the polluting sector sets $x_{t}^{e}$. In the extreme case in which there is no uncertainty about the EA's type, the question of revelation versus secrecy is uninteresting because both actions result in identical social losses.

A salient implication of Proposition 3 is that the EA will actually prefer a system that mandates secrecy about its true preferences regarding the relative benefits of environmental protection versus production of the polluting good. In his book on environmental policy in India, Dwivedi, (1997, p. 104) has noted that many environmental laws "confer enormous discretionary powers on administrative authorities." Propositions 2 and 3 together tell us that in general, this is not a good idea. In particular, our analysis shows that from the DC's perspective, it is better to have an EA that displays commitment to its environmental policy so that the polluting "industries know what to expect [and] how far to go with respect to changing their production processes..." (Dwivedi, 1997, p. 216).

\section{CONCLUSIONS}

In this paper we analyzed two hitherto unstudied questions about the conduct of environmental policy in DCs. First, in the second section, we established the proposition that when faced with a self-financing constraint, an EA should set a constant pollution tax over time. In particular, this means that when its expenditures are unusually high, it is optimal for this EA to run a deficit. Similarly, when its expenditures are unusually low, the EA should run a surplus.

Next, in the third section, we analyzed the notion of credibility in environmental policy. We first demonstrated that environmental policy with commitment results in lower social losses than does discretionary environmental policy. Recently, in the context of India, Dwivedi, (1997, p. 208) has argued that one way to improve environmental policy would be to increase the public's awareness of the different aspects of environmental regulation. In contrast, our analysis shows that society is better off when an EA keeps its preferences about the relative benefits of environmental protection versus production private. This tells us that a certain amount of secrecy in the conduct of environmental policy is a good thing.

The analysis of this paper can be extended in a number of different directions. In what follows, we suggest two possible extensions. First, one could expatiate upon the model of the second section by studying the properties of the EA's optimal tax policy when its expenditures are endogenous. Second, with regard to the model of the third

\footnotetext{
${ }^{* * *}$ Note that it makes sense to perform this computation because on date $t-2$, the EA itself does not know the true value of $\theta_{t}$.
} 
section, it would be useful to study what effects more general loss functions have on the result that it is optimal for the EA to keep its preferences about the relative benefits of environmental protection versus production secret. Studies which incorporate these aspects of the problem into the analysis will provide richer accounts of the theory of environmental policy in DCs.

\section{Acknowledgements}

Batabyal acknowledges financial support from the Gosnell endowment at RIT and from the Utah Agricultural Experiment Station, Utah State University, Logan, UT 84322-4810. The usual disclaimer applies.

\section{References}

Atkinson, G., Dubourg, R., Hamilton, K., Munasinghe, M., Pearce, D. and Young, C. (1997) Measuring Sustainable Development: Macroeconomics and the Environment (Edward Elgar, Cheltenham, UK).

Backus, D. and Driffil, J. (1985) "Rational expectations and policy credibility following a change in regime", Review of Economic Studies 52, 211-221.

Barro, R.J. (1979) "On the determination of the public debt", Journal of Political Economy 87, 940-971.

Barro, R.J. and Gordon, D.B. (1983) "Rules, discretion, and reputation in a model of monetary policy", Journal of Monetary Economics 12, $101-121$.
Batabyal, A.A. (1998) "Environmental policy in developing countries: a dynamic analysis", Review of Development Economics 2, 293-304.

Batabyal, A.A., Beladi, H. (1999) "A dynamic analysis of environmental policy in developing countries in the presence of a domestic distortion," Forthcoming, European Journal of Operational Research.

Bhalla, A.S. (1992) Environment. Employment, and Development (ILO, Geneva, Switzerland).

Dwivedi, O.P. (1997) India's Environmental Policies, Programmes, and Stewardship (St Martin's Press, New York).

Farmer, M.C. and Randall, A. (1997) "Policies for sustainability: lessons from an overlapping generations model", Land Economics 73, $608-622$.

Goldin, I., Winters, L.A., (1996) Models of Sustainable Development (Edward Elgar, Cheltenham, UK).

Goldin, I., Winters, L.A., (1995) The Economics of Sustainable Development (Cambridge University Press, Cambridge, UK).

Heal, G. (1998) Valuing the Future: Economic Theory and Sustainability (Columbia University Press, New York).

Lee, D.M., Batabyal, A.A. (1999) "Dynamic Environmental Policy in Developing Countries With a Dual Economy," Forthcoming, International Review of Economics and Finance.

Mehmet, O. (1995) "Employment creation and green development strategy", Ecological Economics 15, 11-19.

Mehta, S., Mundle, S. and Sankar, U. (1997) Controlling Pollution: Incentives and Regulations (Sage, New Delhi, India).

Obstfeld, M. and Rogoff, K. (1996) Foundations of International Macroeconomics (MIT Press, Cambridge).

Pezzey, J.C.V. (1997) "Sustainability constraints versus "optimality" versus intertemporal concern, and axioms versus data", Land Economics 73, 448-466.

Renner, M. (1992) "Jobs in a sustainable economy," Worldwatch Paper \# 104, Washington DC, USA.

Sinkule, B.J. and Ortolano, L. (1995) Implementing Environmental Policy in China (Praeger, Westport). 


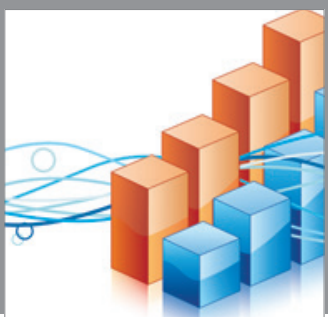

Advances in

Operations Research

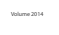

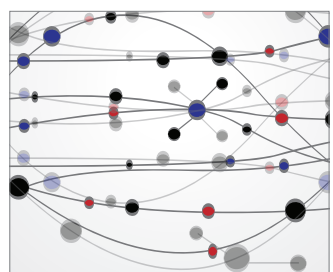

\section{The Scientific} World Journal
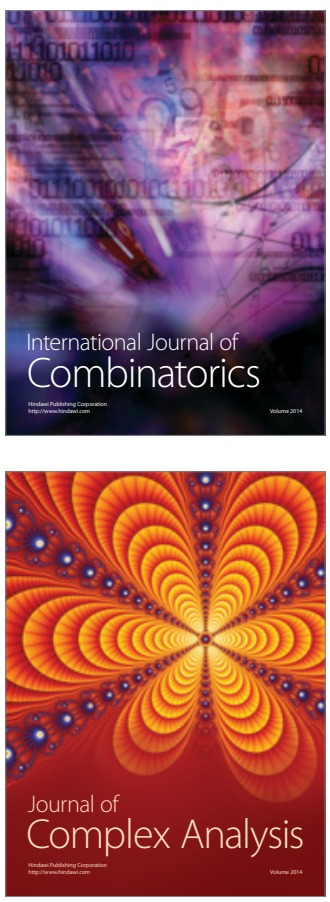

International Journal of

Mathematics and

Mathematical

Sciences
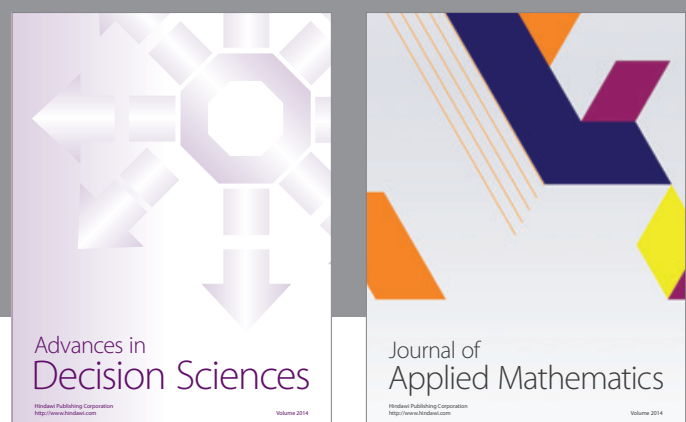

Journal of

Applied Mathematics
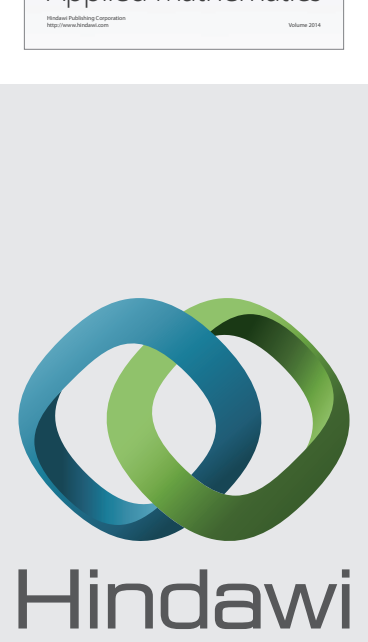

Submit your manuscripts at http://www.hindawi.com
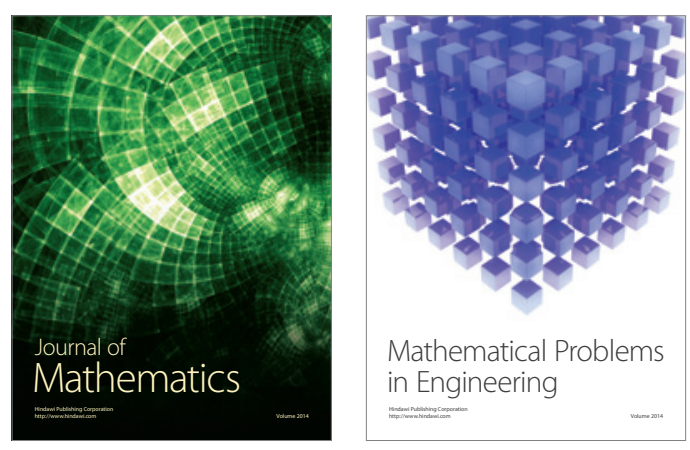

Mathematical Problems in Engineering
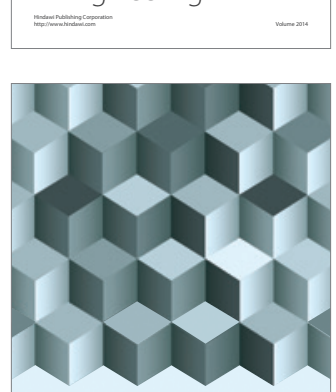

Journal of

Function Spaces
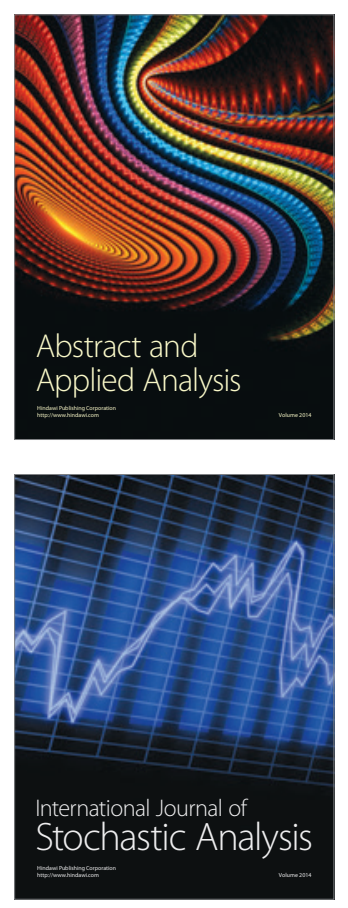

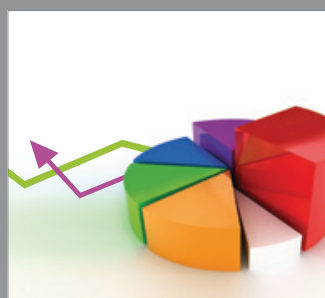

ournal of

Probability and Statistics

Promensencen
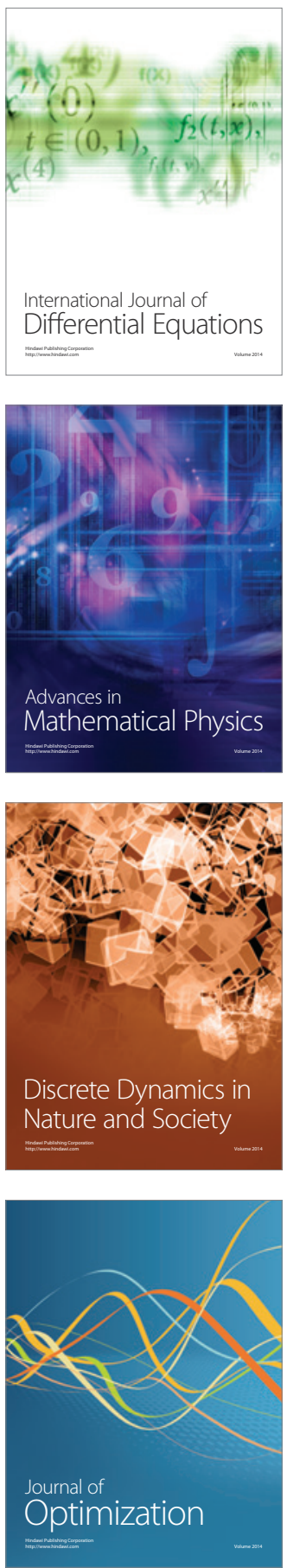